\title{
Dentists could challenge level of ARF
}

Audience members at the Moving Upstream conference held on 30 January 2019 challenged the GDC leadership over the level of the Annual Retention Fee (ARF), asking if it would continue to remain at its present level of $£ 890$.

GDC Chief Executive Ian Brack suggested that everyone would have the opportunity to accept or reject how the regulator proposed to spend money between 2020 and 2022, when its next corporate strategy would be issued for consultation later this year.
'Our costed corporate strategy which we are going to come out for consultation on at high level, will give you an idea of what it is we want to do, what it costs and we will be asking you - alright, if you don't want us to spend this money, how do you want us to do it? What scope of future priorities do you want?' said Brack.

'If you want this priority, we will maximise efficiency to get it for the best cost that we can, but this is the ballpark of what it costs. There is much work being done on this and we will come to you this year with proposals.'

\section{New advice issued on breastfeeding and dental decay}

Dentists are being advised to read new guidance ${ }^{1}$ from Public Health England (PHE) summarising the evidence on breastfeeding and dental health.

In July 2018, the Scientific Advisory Committee on Nutrition (SACN) published its report Feeding in the first year of life $e^{2}$ which gave the latest evidence on nutrition, diet and health and included a review of the evidence on dental caries and breastfeeding.

It concluded that breastfeeding in the first year of life is associated with a decreased risk of dental caries and in order to support dental teams in advising families on this topic, PHE has developed its updated evidence summary on breastfeeding and dental health and an infographic.

PHE said dental teams had a key role in supporting mothers to breastfeed and giving consistent advice on infant feeding.

They should be advising mothers to breastfeed exclusively for six months and at this stage, solid foods could be introduced alongside continued breastfeeding. A wide range of foods should be introduced avoiding sugary foods and drinks. A cup can also be introduced from six months but only with breast milk, infant formula or plain water.

PHE also recommended that dental professionals emphasise that breastfeeding is good for oral and general health and that when a mixed diet is established, to avoid sugary foods and drinks. Parents should start brushing their child's teeth as soon as the first tooth has erupted with fluoride toothpaste and visit the dental team for advice and care.

Making a dental practice breastfeeding friendly can be simple and let women know that they are supported, said PHE. Many women felt nervous about breastfeeding in public so practices could show that they welcomed and supported this by displaying an easily recognisable sticker and sharing information about why breastfeeding is important. More information is available by visiting the breastfeeding network's

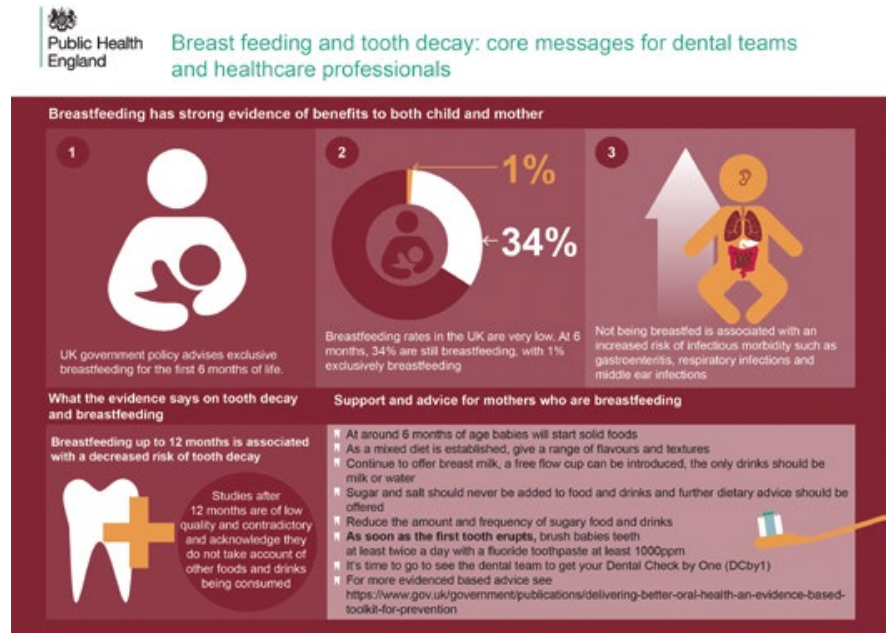

breastfeeding friendly scheme. ${ }^{3}$

The consideration of children breastfed beyond 12 months was not within the remit of the SACN evidence review but it will shortly be reviewing the evidence for children aged 12-60 months including oral health.

\section{References}

1. Public Health England. Guidance: Breastfeeding and dental health. 2019. Available at https://www.gov.uk/government/publications/breastfeeding-and-dental-health/breastfeeding-and-dental-health (accessed February 2019).

2. Scientific Advisory Committee on Nutrition. Feeding in the First Year of Life: Crown copyright. 2018. Available at https://www.gov.uk/government/publications/feeding-inthe-first-year-of-life-sacn-report (accessed February 2019).

3. The Breastfeeding Network. BfN Breastfeeding Friendly Scheme. 2017. Available at https://www.breastfeedingnetwork.org.uk/bfn-breastfeeding-friendly-scheme/ (accessed February 2019).

\section{Dental annual meeting announced}

The Society of Manchester Dental Alumni (SOMANDA) is to hold its Biennial Meeting on 5 April 2019 entitled 'Too Much Law - Too Little Justice' at the newly-built Crowne Plaza Hotel Manchester Oxford Road at 55 Booth Street West, Manchester.

There will be a choice of symposium or hands-on workshops followed by university tours, including the newly refurbished Coupland 3 Dental School space, and dinner.
Speakers for the symposium will be Matthew Hill, Executive Director for Strategy at the General Dental Council, and Paul Lambden, Head of Patient Liaison for BUPA UK Dental. The hands-on workshops will be run by Craig Jack and Gavin McManus.

More details are available by emailing Ian Wood at idwood@ hotmail.com. 